\title{
From Knowledge Navigator and Watson to Star Trek: The role of the information professional $^{1}$
}

\author{
Bonnie C. Carroll \\ Information International Associates, Inc., Oak Ridge, TN, USA \\ E-mail: bcarroll@iiaweb.com
}

We have been given a formidable challenge. We have been asked to look to the future we want to see, not necessarily predicting what might happen. At the same time and at the end of the day, we have been asked how to prepare students to invent the future. And to bring it all home, we have been asked to help identify a set of key challenges and recommendations for courses, activities and experiences to meet those challenges. As we go along, perhaps some of the questions are as important as any single answers.

My context in this is the information industry, but a very specialized marketplace in this industry. My company does information management and information technology support services for federal agencies. We focus on scientific and technical information management. The direct relevance is we regularly engage practicum students and hire graduates from schools of library and information sciences. But we also hire computer scientists, and subject matter experts. And ideally we look for combinations of the three. So, let's begin. We're talking about 2050, so let's imagine:

In looking at the future we want to see, it might be good to start with some scenario review. In 1989 we had the "Knowledge Navigator" (www.youtube.com/watch?v=HGYFEI6uLy0), the scenario of the information future at that time. The Navigator had an Avatar who helped the hero navigate through information as well as personal schedules and life. Not too unlike our iPhones today with all our applications and it even included a voice response not unlike a good Siri. And we all shook our heads and saw all of the obstacles to that future. Remember there was no Internet, no World Wide Web and no Google.

Today we have Watson. An information machine that answers questions better than smart human beings. Again we see the constraints and challenges to expanding the scope of knowledge. But is this just the universe of knowledge or is it the kind of knowledge?

And then we have Star Trek where the computer is the fount of knowledge and can answer any question. But we see that as rather far out. Looking at how past futures have come into reality, it's not so far-fetched to think that 2050 might see more of "Computer" than Watson.

So the first question might be whether Star Trek is so bad? Other than the earth destroyed and wars continuing, is the information future where we want to go? The second is whether it is inevitable? And if we go to the future where all the information seeker has to do is ask a "machine", then what is the role of the information professional?

\footnotetext{
${ }^{1}$ This work is licensed under the Creative Commons Attribution-Noncommercial No Derivations Works 3.0 Unported license. You are free to Share this work (copy, Distribute and transmit) under the following conditions: attribution, noncommercial and no derivative works. To view a copy of this license, visit http://creativecommons.org/licenses/by-nc-sa/3.0/.
} 
Or here is another vision of the information future: The print world talks of "food for thought". In the networked world users will be the prey and information the predator. ${ }^{2}$ That's a pretty aggressive Computer! But we're on our way with recommendation systems that are pervading more and more of our information seeking functions.

However far we get by 2050, it is clear that we will be a paperless (not me but the next generation), wireless, and mobile society. We will expect and get our information anytime and anywhere. It will not be the "document" that contains the information but the information itself.

Clearly libraries as we thought of them in the past are out - in fact they are already far in the process of transformation. Are librarians, who are now more broadly associated or interchanged with Information Professionals including information scientists, archivists, records managers, and some computer scientists, also out? A segment of librarians have not been traditional for a long time. When everything started having a fully digital life cycle, librarians have continued to carry on basic technical services functions, including collection, technical processing and knowledge organization, and information dissemination and retrieval. On the user services side there continues to be the function of education, training, reference and even circulation (think e-books and user controls). But the technologies and the means by which these functions are carried out have changed radically. This has meant adding new skill sets, mainly technology driven, to the mix. Even in the most traditional of reference functions, social media has transformed the way this can be done.

Technologies have been disruptive and it is critical for information professionals to stay up on changes in technologies. Figure 1 shows the rapid rate of change in technologies and each of us can overlay our views on how these have changed the roles of information professionals.

We may not be the developers of these technologies, although our knowledge organization expertise has been sought after by the "big ones" after they realized that the machine needs to better understand the structure of knowledge to be better guided to the human interface.

So what are the key challenges? Clearly there are many, but I will highlight four. The higher information literacy and expectations of the users that have been enabled by such disruptive technologies. First, search engines like Google and now social media like Facebook, have changed the playing field. Not in 38 years but for the next 10 years we're going to have to rethink children's "reading rooms" because those age groups are digital natives and baby boomer's "reading rooms" because we are the digital immigrants. They will be in power in 2050 , but we are in power now. The information professional will need to rethink providing services to accommodate a rapidly changing user profile.

Another major challenge is information overload. We hear daily about the data deluge and the amount of information that is more than we can absorb. But even this is not a new phenomenon. What is new is the degree and kind. And some of the solutions like data visualization, data analytics, and data mining are based in technologies. Just as the mechanical machine enabled the industrial revolution and extended human physical power, the computer has forced the information revolution and will extend our mind power. So information professionals will need to have the skills to address this information overload for the next generation - until "Computer" really holds the day.

The third challenge is the total globalization of knowledge and the dramatic changes it brings. Particularly here in the United States we are facing a brave new world. For my generation, English has always been the language of science and the language of commerce. This wasn't always true and when one looks at world demographics, we can wonder what it will be like in 2050. We have economic competition and national security concerns. We have cyber warfare both in the boardroom and in the military. We have

\footnotetext{
${ }^{2}$ In a conversation with a colleague from the Coalition for Networked Information (Paul Peters, 1993, oral communication).
} 


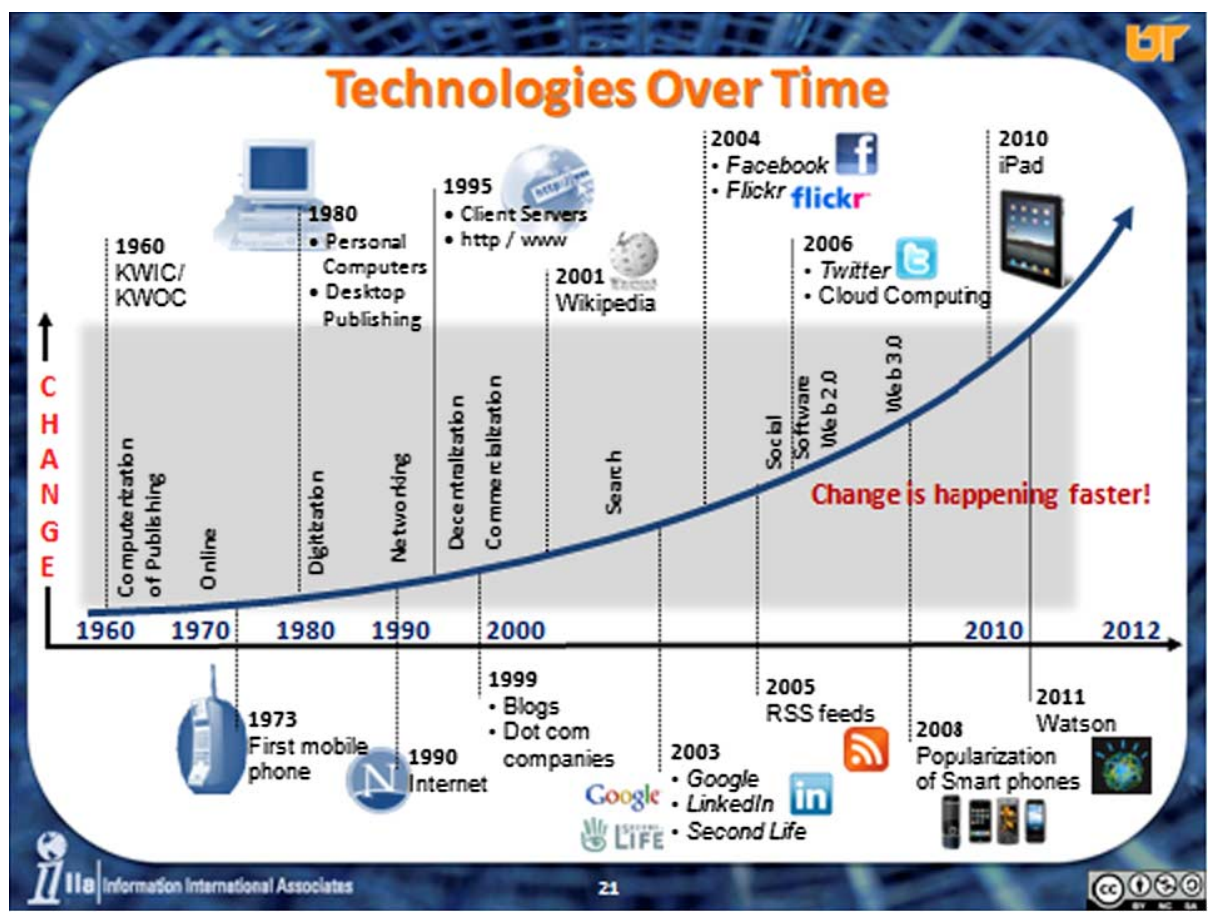

Fig. 1. The rapid rate of change in technologies over time. (Colors are visible in the online version of the article; http:// dx.doi.org/10.3233/ISU-2012-0667.)

cross-cultural and multi-lingual challenges to deal with today. Think of the Wal-Mart cashiers and note that even in the US, even in the small towns in Tennessee, we must choose between English and Spanish. In scientific information, the demographics of authorship are dramatically changing. Clearly, the US information professional will face some unique challenges as we engineer our information systems of the future.

The final challenge deals with the broader cultural changes taking place in the social cyber world; with a key emphasis on intellectual property and personal privacy. What will the future property regimes look like and how will the work that the information professional will do be impacted by these changes? We already see evidence that the digital generation has a very different sense of intellectual property and sharing of information. There is an orientation toward openness and borderlessness. But we also see a tightening of international patent and copyright interests to protect what the current generation has invested in. How will all of this factor into the role of each information professional as s/he enters the world of work - and into the information systems that will be built?

So what are recommendations for courses, activities and experiences to prepare students to meet workforce challenges? Clearly the more technology and tools we understand, the better. But specific tools will be constantly changing. So it is also important to teach insight and understanding of them in the context of the information life cycle and the kinds of needs served by these various functions as mentioned previously. Opening up interfaces with mathematical and computer science tools, including simulation and modeling, will allow the information professional to participate in the building of Watsons and will add a depth to the information professional's understanding.

It is also important to maintain perspective on different user communities. Traditional courses in sciences, social sciences and humanities will have an important place to understand the special nature of 
different user groups. But the boundaries among disciplines are breaking down in our flat and fluid information world. In each disciplinary class or perhaps as a follow-on it is important to teach information needs in interdisciplinary problem solving of macro problems of the day like global change, deficit reduction as well as thinking about micro problems like competitive business intelligence for a specific company.

Cross-cultural exposure and perspectives are also important to include in the curriculum, both within individual courses and in other ways. Perhaps some element in the curriculum that exposes the students to thinking about the future just as we will be discussing at IP2050 will help prepare them for the rapidly changing world they will be entering. The one constant is that the rate of change is increasing. Giving some perspective on the history of change can be enlightening.

In addition to course content, it is also clear that a lot of the training of today's S/I school graduates is being done virtually. From almost all virtual to only some on-line courses, the media is increasingly part of the message. It is a transition for digital immigrants, but probably more normal for the next generation. Thinkers about the future of the University are dealing with such problems at the higher levels and perhaps information professionals should be leading the way in this kind of thinking since information is the currency of the learning process.

And finally, as part of all programs for those information professionals who are looking at a terminal masters level professional degree to enter the workforce, it is important to gain work experience. Student practicums and internships (paid or unpaid) as well as bringing real problem solving into the classroom are good tools to improve a resume in principle and the graduates abilities in fact. Most schools have such programs, and this will be increasingly important in the future. This has been impacted by the job market competition where graduates must find ways to differentiate themselves. Perhaps by 2050, the training and hands-on doing will be even more integrated. One should also add a cross-cultural experience to real world experiences. This can be done by studying abroad or organized tours as part of a classroom experience. Perhaps we should think of cross-cultural as not only international but also exposure to work communities. In the case of the world for which we hire, one should have tours of scientific and/or intelligence environments. A lot of this is being done, so the recommendation is to support and enrich these directions.

In reviewing the courses and programs of a few schools in preparation for IP2050, we see that change has been taking place. There are elements that address most of the challenges that have been presented. It is most difficult to begin with 2050 and bring it home with current program development. But getting the discussion going is a great start. 